BMJ Paediatrics Open

\section{Management of neonatal jaundice in low- income and middle-income countries}

To cite: Erdeve 0. Management of neonatal jaundice in low-income and middle-income countries. BMJ Paediatrics Open 2020;4:e000845. doi:10.1136/ bmjpo-2020-000845

Received 20 September 2020 Revised 16 0ctober 2020 Accepted 20 0ctober 2020
Check for updates

(C) Author(s) (or their employer(s)) 2020. Re-use permitted under CC BY-NC. No commercial re-use. See rights and permissions. Published by BMJ.

Division of Neonatology, Department of Paediatrics, Ankara University School of Medicine, Ankara, Turkey

Correspondence to Dr Omer Erdeve; omererdeve@ yahoo.com
Neonatal jaundice (NJ) is a physiological process that occurs normally in many infants, whereas it becomes pathological and imposes an increased risk of both short-term and long-term morbidities such as hospitalisation expenses, risks of hearing loss and kernicterus, and even mortality in some cases. The challenges are especially acute in low-income and middle-income countries (LMICs), where the burden of the disease is greatest and medical facilities are least equipped to manage severe NJ. Healthcare system characteristics related to organisation, reality of the national data registries, national budget priorities, reserved budget for health effect, rate of healthcare professionals to population and availability of an insurance system have a direct effect on the problem. In addition, risk factors vary significantly in LMICs because of being very heterogeneous and having different dynamics in various aspects, such as race-related diagnosis difficulties (especially black race), religion and cultural beliefs, geographical and climate-related issues. Although the true worldwide dimension of the problem is not known, $\mathrm{NJ}$ is still reported as a life-threatening condition in many countries. Depending on geographical location and genetic background, NJ can result from different aetiologies which may show variation even within regions of the same country. ${ }^{12} \mathrm{~A}$ modelling study which was published in 2016 estimated that extreme hyperbilirubinaemia, including haemolytic aetiologies, might be responsible for a mortality rate of 1.19 over 1000 live births in LMICs in comparison to 0.01 over 1000 live births in high-income countries (HICs). The prevalence of kernicterus in sub-Saharan Africa, Latin America, Eastern Europe/Central Asia and South Asia regions was estimated as high as $0.73 / 1000$ in comparison to $0.1 / 1000$ live births in HICs. ${ }^{2}$ Abilities to increase awareness on the identification of the requirements and willingness to improve management of the health system can result in reduction in complications of severe NJ and improve opportunities for many newborns all around the world. The first step in the prevention of NJ is the identification of predisposing factors. Many national and hospital-based studies in the literature report a high proportion of unknown factors in aetiology of severe hyperbiliburinaemia, which points either lack of application to the health service or availability of laboratory evaluations. $^{1-3}$

This editorial highlights two articles which demonstrate the unique challenges and other important aspects of $\mathrm{NJ}$ in Africa. The first article, an institution-based unmatched casecontrol study design which was employed on 447 neonates at five referral hospitals in Northern Ethiopia, showed that prolonged duration of labour, being male, having a low birth weight, birth asphyxia, sepsis/infection and hypothermia were the risk factors for NJ. This study demonstrates the accompanying neonatal morbidities that may aggravate the influence of NJ in LMICs. Early recognition and treatment of identified modifiable determinants to prevent complications related to $\mathrm{NJ}$ gain great importance in such areas. ${ }^{4}$ Clinicians and researchers in LMICs should be encouraged to continue to systematically and rigorously study $\mathrm{NJ}$ in order to recognise it in a timely fashion and to prevent its tragic consequences. This kind of data will aid healthcare professionals in assessing the prevalence of hyperbilirubinaemia in their population and hopefully allow them to properly allocate resources to combat this neonatal affliction. Indeed, national health systems and international agencies should recognise $\mathrm{NJ}$ as a priority and invest resources to address this tragic and largely preventable condition. ${ }^{1-3}$ Despite its frequency, in fact few root cause analyses of NJ using national registries have been performed. Erdeve etal conducted a nationwide root cause analysis of $\mathrm{NJ}$ in Turkey and found several noteworthy observations, such as the two most common risk factors for $\mathrm{NJ}$ were a haemolytic aetiology 
followed by lack of initiation of proper breastfeeding, and recommended blood type screening and adequate follow-up during the first week of life to national healthcare system. ${ }^{3}$ A meta-analysis on risk factors for severe neonatal hyperbilirubinaemia in LMICs also showed that infants at risk of severe hyperbilirubinaemia in LMICs are associated with maternal and neonatal factors that can be effectively addressed by available interventions to curtail the disease burden prevailing in the affected countries. ${ }^{5}$

The second article, a meta-analysis incorporating the studies involving African patients, demonstrated that the overall magnitude of $\mathrm{NJ}$ was $28 \%$ in sub-Saharan Africa. Neonates with glucose-6-phosphate dehydrogenase (G6PD) deficiency (OR 2.42, 95\% CI 1.64 to 3.56) and neonates that had a blood type that was incompatible with their mother's (OR 3.3, 95\% CI 1.96 to 5.72) were more likely to develop hyperbilirubinaemia. ${ }^{6}$ Estimated rates for aetiologies of extreme hyperbilirubinaemia were listed as Rh disease (78\%), G6PD deficiency (6\%), moderate/late preterm birth $(2 \%)$ and $15 \%$ to other causes in a modelling study. Additionally, $80 \%$ of affected infants were expected to be in countries with a mortality rate of $>15 / 1000$ live births. ${ }^{2}$ Different studies reported that in HICs, fetomaternal blood group incompatibilities are the leading cause of NJ, but in LMICs, the case is different as it is mostly prematurity, low birth weight, birth trauma, $\mathrm{ABO}$ incompatibility, sepsis as well as effects of herbal medications in pregnancy and application of dusting powder on baby may result in G6PD deficiency, which is one of the most important causes of NJ in Africa and Asia. A high prevalence of G6PD deficiency, combined with exposure to oxidants (eg, mothballs and menthol creams), is a major cause of haemolytic jaundice, in addition to $\mathrm{ABO}$ incompatibility and $\mathrm{Rh}$ isoimmunisation in LMICs. ${ }^{2}{ }^{6}$ Therefore, early identification and care strategies should be developed for the newborns affected by G6PD deficiency and blood type incompatibility. WHO recommends a universal screening programme in all regions with a prevalence of G6PD deficiency of $3 \%-5 \%$ or more in men. Low-cost interventions remain feasible where routine blood type testing and universal G6PD deficiency screening are currently unavailable. It is obvious that parallel to the heterogeneity of LMIC, offered low-cost interventions may not be so low-expense let alone so easy, especially 'education of parents and heathcare workers' is a very complicated subject that may be affected by multiple factors changing with time and region. In addition, appropriate postnatal follow-up of newborns is also difficult to manage even in HIC due to requiring up-to-date protocols. But, public awareness and parental training for the identification of the signs of NJ, together with proper training for healthcare providers and follow-up of newborns, can contribute significantly to reducing the high prevalence of severe $\mathrm{NJ}$ and its complications in low-resource settings. ${ }^{12}$

It is clear that a worldwide strategy to prevent NJ-related neurological damage and mortality by early diagnosis and appropriate management should combine data from internationally developed frameworks and adapt them to local conditions and capacities. Local data can then be interpreted for identifying the priorities and interventions for national policy and practice.

\section{Twitter Omer Erdeve @omererdeve}

Contributors Dear Editor, As an sole author, I have substantial contributions to the conception or design of the editorial, interpretation of data for the work, drafting the work and revising it critically for important intellectual content; and final approval of the version to be published. I agree to be accountable for all aspects of the work in ensuring that questions related to the accuracy or integrity of any part of the article are appropriately investigated and resolved. Best,Omer Erdeve.

Funding The authors have not declared a specific grant for this research from any funding agency in the public, commercial or not-for-profit sectors.

Competing interests None declared.

Patient and public involvement Patients and/or the public were not involved in the design, conduct, reporting or dissemination plans of this research.

\section{Patient consent for publication Not required.}

Provenance and peer review Commissioned; externally peer reviewed

Open access This is an open access article distributed in accordance with the Creative Commons Attribution Non Commercial (CC BY-NC 4.0) license, which permits others to distribute, remix, adapt, build upon this work non-commercially, and license their derivative works on different terms, provided the original work is properly cited, appropriate credit is given, any changes made indicated, and the use is non-commercial. See: http://creativecommons.org/licenses/by-nc/4.0/.

ORCID iD

Omer Erdeve http://orcid.org/0000-0002-3193-0812

\section{REFERENCES}

1 Bhutani VK, Zipursky A, Blencowe H, et al. Neonatal hyperbilirubinemia and rhesus disease of the newborn: incidence and impairment estimates for 2010 at regional and global levels. Pediatr Res 2013:74(Suppl 1):86-100.

2 Greco C, Arnolda G, Boo N-Y, et al. Neonatal jaundice in low- and middle-income countries: lessons and future directions from the 2015 Don Ostrow Trieste yellow retreat. Neonatology 2016;110:172-80.

3 Erdeve O, Okulu E, Olukman O, et al. The Turkish neonatal jaundice online registry: a national root cause analysis. PLoS One 2018;13:e0193108.

4 Bizuneh AD, Alemnew B, Getie A, et al. Determinants of neonatal jaundice among neonates admitted to five referral hospitals in Amhara region, Northern Ethiopia: an unmatched case-control study. BMJ Paediatr Open 2020;4:e000830.

5 Olusanya BO, Osibanjo FB, Slusher TM. Risk factors for severe neonatal hyperbilirubinemia in low and middle-income countries: a systematic review and meta-analysis. PLoS One 2015;10:e0117229.

6 Aynalem YA, Mulu GB, Akalu TY, et al. Prevalence of neonatal hyperbilirubinaemia and its association with glucose-6-phosphate dehydrogenase deficiency and blood-type incompatibility in subSaharan Africa: a systematic review and meta-analysis. BMJ Paediatr Open 2020;4:e000750. 